\title{
Floristic Composition, Diversity and Stand Structure of Tropical Forests in Popa Mountain Park
}

\author{
Yu Ya Aye ${ }^{1,2^{*}}$, Savent Pampasit ${ }^{2}$, Chanin Umponstira'2, Kanita Thanacharoenchanaphas ${ }^{2}$, \\ Nophea Sasaki ${ }^{3,4}$ \\ ${ }^{1}$ Forest Research Institute, Forest Department, Ministry of Environmental Conservation and Forestry, \\ Naypyitaw, Myanmar \\ ${ }^{2}$ Department of Natural Resources and Environment, Faculty of Agriculture, Natural Resources and \\ Environment, Naresuan University, Phitsanulok, Thailand \\ ${ }^{3}$ Graduate School of Applied Informatics, University of Hyogo, Kobe, Japan \\ ${ }^{4}$ School of Earth and Environmental Sciences, University of Adelaide, Adelaide, Australia \\ Email: yuyaaye@gmail.com
}

Received 3 October 2014; revised 1 November 2014; accepted 15 November 2014

Copyright (C) 2014 by authors and Scientific Research Publishing Inc.

This work is licensed under the Creative Commons Attribution International License (CC BY). http://creativecommons.org/licenses/by/4.0/

(c) (i) Open Access

\begin{abstract}
Safeguarding biodiversity is an important component of the REDD+ scheme of the United Nations Framework Convention on Climate Change. Information on tree species and their distribution is therefore needed for successful implementation of forestry carbon projects. Forest inventory data were collected in four natural forests located in Popa Mountain Park, Myanmar. Based on the data from 4-ha sample plots, average stem density ranges from 1293 trees ha-1 in dry dipterocarp forest to 804 tree ha-1 $^{-1}$ in dry evergreen forest. According to the Jackknife estimator for species richness (trees with DBH $\geq 5 \mathbf{c m}$ ), the highest number of species was recorded in dry mixed deciduous forest-74 species ha-1, and the lowest number of species recorded in dry forest-40 species ha-1. Dry mixed deciduous forest occupied the highest value on the Shannon-Wiener index and Simpson diversity index while the lowest was in dry forest, indicating that dry mixed deciduous forest is the most complex whereas dry forest is the simplest community. Not only does this study provide useful information on the current status of vegetation type but the information is important for designing forestry management systems that could result in biodiversity conservation and carbon emission reductions.
\end{abstract}

\section{Keywords}

Safeguarding Biodiversity, Species Richness, Forest Conservation, Natural Forest, Myanmar

\footnotetext{
*Corresponding author.

How to cite this paper: Aye, Y.Y., Pampasit, S., Umponstira, C., Thanacharoenchanaphas, K. and Sasaki, N. (2014) Floristic Composition, Diversity and Stand Structure of Tropical Forests in Popa Mountain Park. Journal of Environmental Protection, 5, 1588-1602. http://dx.doi.org/10.4236/jep.2014.517150
} 


\section{Introduction}

Conservation of natural forest resources is an important component of climate change mitigation strategies in the region [1]. For a good forest conservation plan, understanding tree species composition and knowledge of the forest stand structure is necessary [2] because forest composition and species population sizes show species tolerance of prevailing environmental conditions, particularly rainfall and soils in addition to local site history [3]. Tropical forests are especially affected by the activities and needs of local people [4]. Demand for wood and non-wood forest products increases along with increasing population [5]. These activities vary over time and space [6] and also have different degrees of impact on forest vegetation [7]. Due to overexploitation and deforestation, tropical forests are disappeared at an alarming rate. Between 1990 and 2005, tropical forests lost about 13 million hectares a year [8] and deforestation and forest degradation were the main cause of species extinction [9]. Tropical deforestation and forest degradation have brought international concern over forest composition and tree species. Safeguarding local benefits and biodiversity is an important requirement for carbon project development under the reducing emission from deforestation and forest degradation, sustainable management of forests and enhancement of forest carbon stocks (REDD+) of the United Nations Framework Convention on Climate Change (UNFCCC). Therefore, monitoring changes of tree diversity and forest structure becomes important for the successful implementation of any REDD+ scheme because REDD+ scheme focuses not only on reducing carbon emissions, but also on safeguarding biodiversity and socio-economics of forest dependent communities in developing countries.

Biodiversity inventories are used to determine the nature and distribution of biodiversity resources of the forests to be managed [10]. Using resource inventory as a basis of stand structure, species composition and dynamic is important for development of strategies for achieving sustainable management of forests [11]. Furthermore, species diversity is one of the analytical tools applied in determining the degree of variability of tree species within a community or a region [12]. Quantifying tree species distribution and abundance is also an important aspect of forest conservation as they contribute to the structural characteristics of the forest [13]. Nevertheless, forest inventory data in developing countries are not up to date because the concerned forests become degraded, fragmented or patchy soon or later after logging [3]. Therefore, it is critical to examine the current status of species diversity using latest inventory data as such data will provide appropriate guidelines for developing effective system of forest conservation and forest management.

Myanmar is a heavily forested country with the high rate of deforestation of $0.93 \%$ annually in the last decade 2000 and 2010 [8]. Forests and biodiversity in Myanmar have been under severe pressure due to population growth accompanied by increase in resource use and increasing demand for timber resources from neighbouring countries [14]. Various studies suggest that protected areas (PAs) can play a crucial role in conserving the biodiversity of Myanmar [15] and are an effective approach for reducing deforestation and forest degradation [16]. This study was conducted in Popa Mountain Park (PMP hereafter). Located in central Myanmar, PMP is acknowledged as containing high diversity of plants in Myanmar. Some locations in PMP were found to have the high diversity of plant species. In western park and some crater areas of PMP, about 300 species were recorded in 1992 [17] and 221 species were recorded in 1997 at a location in the crater area [18]. Information on tree composition and diversity of tree species is of primary importance in the planning and implementation of biodiversity conservation efforts and forest management [19]. Despite having been recognized as having the highest species diversity in Myanmar, there is no information on floristic composition, tree density, basal area, species richness and diversity for natural forests in the PMP. This paper investigated in four natural forest types in PMP and stand structures in each type were analyzed in order to determine the level of species composition, diversity and distribution in the area. Information from this study will provide a valuable reference for appropriate forest conservation that will result in reducing deforestation and forest degradation.

\section{Methods}

\subsection{Study Area}

The research was carried out at Popa Mountain Park (PMP), where high diversity of plants (including medicinal plants) were found. The area was classified by Myanmar's forest department as forest reserve in 1902. Popa Reserve was proposed as protected area by the Nature Conservation National Park Project conducted between 1981 and 1984. The area was subsequently declared a Protected Area in 1989. The park covers an area of about 
10,000 ha, of which $88.7 \%$ is covered by forest [20]. Elevation ranges from about 300 to $1500 \mathrm{~m}$ above sea level. Mean maximum and minimum monthly temperatures respectively are $31.30^{\circ} \mathrm{C}$ and $8.52^{\circ} \mathrm{C}$ and the mean annual rainfall is about $1170 \mathrm{~mm}$ (Popa Forest Department office, 2013, unpublished data). The PMP includes a diverse range of vegetation types such as dry mixed deciduous forest, and dry dipterocarp forest (scrub indaing forest), dry forest (Than-dahat forest) and dry hill or evergreen forest [20]. All forests in PMP are second or third growth forests as results of timber harvesting and clearing for agriculture in the early twentieth century [21].

A volcanic plug at the western foot of Mount Popa or Taung-kalat in local name, is a prominent landmark and widely known as a religious site for local people. Popa Mountain Park is also an important watershed for the surrounding area (especially for Kyaupadaung Township). Therefore, Popa Mountain Park was designated as a protected area for conservation of the forest, protection of the watershed of the Kyet-mauk-taung dam located at the southern edge of the park, conservation of medicinal plants for sustainable use, preservation of existing religious sites and to ensure sustainability of water sources, including natural springs [22]. To provide better protection for the forest within the area, and to regulate the local use of vegetation outside the boundary, an area of 10,360 ha was established as a buffer zone surrounding the Park in 2010. There are 45 villages located in the surrounding areas of the park. The major agricultural practices on the eastern side are cultivation of bananas, fruits and other seasonal crops, while the main activities on the west side are cultivation of rain-fed rice paddies, palm-sugar production, small-scale fisheries, and seasonal crops [23] (Figure 1).

\subsection{Vegetative Inventory}

Data for this study were collected from dry mixed deciduous forest, dry dipterocarp forest, dry forest and dry hill or evergreen forest. Twenty five sample plots, each with an area of $400 \mathrm{~m}^{2}(20 \mathrm{~m} \times 20 \mathrm{~m})$ were laid out in each forest type. The height $(\mathrm{Ht})$ and diameter at breast height $(\mathrm{DBH})$ of all trees $(\mathrm{DBH} \geq 5 \mathrm{~cm}, \mathrm{Ht} \geq 1.3 \mathrm{~m})$ were measured in each plot. “A Checklist of the Trees, Shrubs, Herbs and Climbers of Myanmar” [24] was used to identify plant species by botanical and local names with assistance of taxonomic experts.

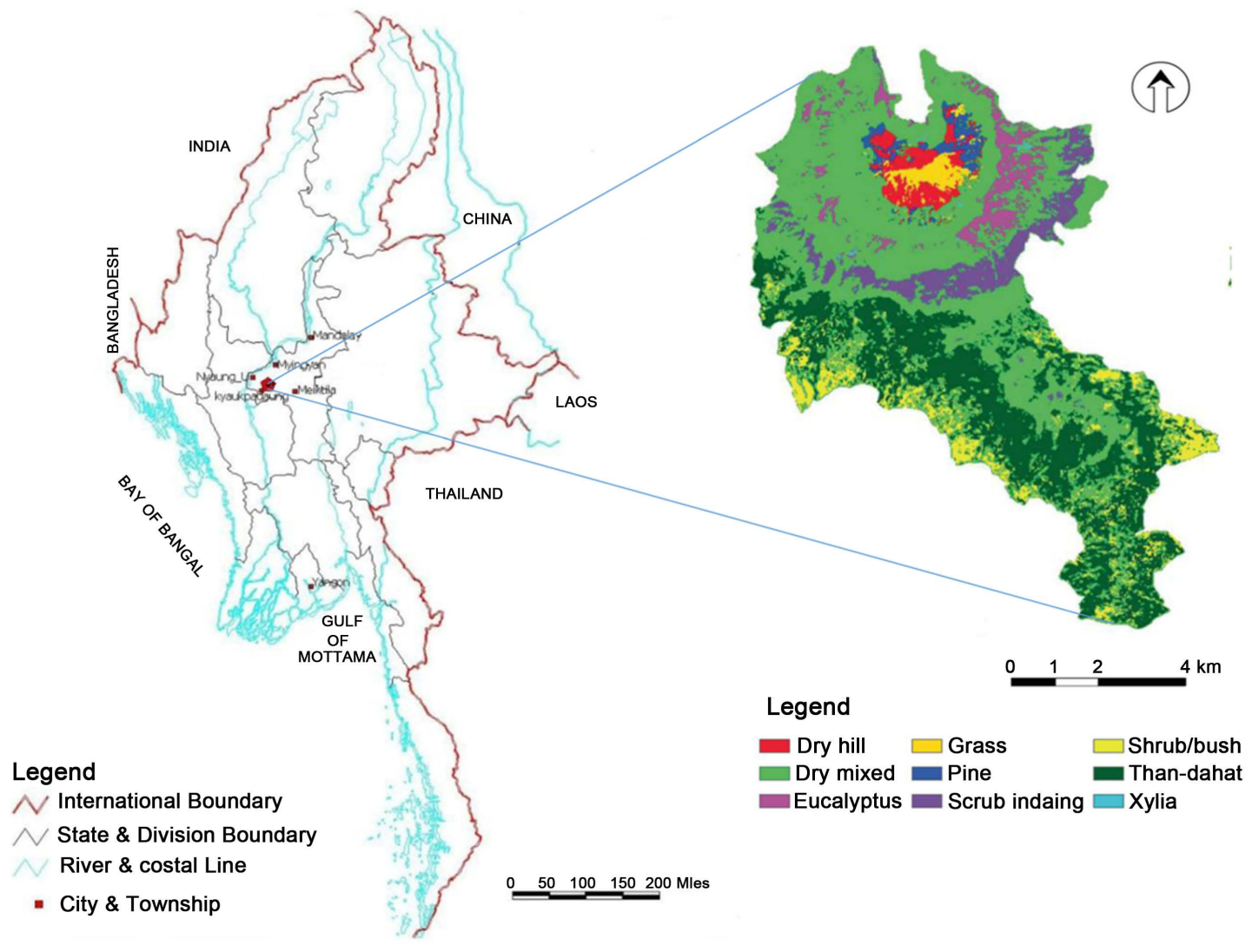

Figure 1. Location map of the study area. 


\subsection{Data Analysis}

The data were analyzed for species composition, richness, diversity, species Importance Value Index (IVI). The species richness were estimated using the Jackknife estimator [25]. To provide quantitative estimates of plant diversity, Simpson's index [26] and Shannon's index [27] were used. Evenness indices, which are a structural composition index reflecting the dominance of species were also calculated. The Sorenson's quantitative index which accounts for the relative abundance of shared species was used to assess the degree of floristic similarity within and between the forest stands [28]. For assessing the ecological importance or significance of a species, the IVI were used [29]. To assess taxonomic and structural composition between the forest types, the IVI value was calculated at the level of families. Family important values was computed as the average of the relative basal area, density and frequency.

\section{Results}

\subsection{Species Richness and Diversity}

Species richness is the basic component of diversity of any community [30]. The Jackknife estimator for species richness of trees (DBH $\geq 5 \mathrm{~cm}$ ) showed that dry mixed deciduous forest (DMDF) occupied the greatest number of species (74 species) followed by dry dipterocarp forest (DDF) (53 species), dry forest (DF) (45 species) and dry hill/evergreen forest (DHEF) (40 species) (Table 1). Our findings of tree species are in the range of that found in mature tropical forest, $56-282$ species $\mathrm{ha}^{-1}(\mathrm{DBH} \geq 10 \mathrm{~cm})$ [31]. Our findings are also in line with other study [32] in five tropical dry forests on Oceanic islands. Their study found 242 species ha $^{-1}$ (DBH $\geq 2.5$ $\mathrm{cm}$ ) in New Caledonia, 112 species ha ${ }^{-1}$ in Fiji, 39 species ha ${ }^{-1}$ in the Mariannas, 24 species ha ${ }^{-1}$ in the Marquesas and 96 species $\mathrm{ha}^{-1}$ in Hawaii. But our findings are lower than that found in dry tropical forests of India, where 190 species ha $^{-1}(\mathrm{DBH} \geq 5 \mathrm{~cm})$ were recorded [33] and 105 species ha ${ }^{-1}(\mathrm{DBH} \geq 10 \mathrm{~cm})$ were found in the tropical seasonal forest in Khao Yao National Park in Thailand [34]. The difference may be due to the forest locations and tree size (i.e. DBH) recorded during forest inventory. We enumerated trees with only having above $5 \mathrm{~cm} \mathrm{DBH}$. The difference in terrain, gradient and slope direction causes differences in the soils, water and microclimate which causes differences in species adaptability [19].

Tree diversity inclines provide important information about rarity and commonness of species in a community [19]. Shannon's diversity index (H') places more weight on the rare species while Simpson's diversity index (1-D) gives more weight to those species which occur more frequently [28] [35]. In Popa Mountain Park, DMDF occupied the highest value of Shannon-Wiener index and Simpson diversity index, 3.61 and 0.96, respectively. Both diversity indexes indicated that the species diversity of DMDF is the highest among all forests in PMP. The larger the value of H', the greater the species diversity and vice versa [36]. The Shannon-Weiner diversity Index (H') value stood at 3.61 in DMDF, 2.96 in DDF, 1.45 in DF and 2.41 in DHEF, indicating that among forest types, DMDF was the most complex in species diversity whereas DF is the simplest community in term of species composition. This implies that elevation and aspect favors diversity and may be partly responsible for the diversity index obtained at Popa Mountain Park.

Our study findings are in line with the findings of Bhat [37] in the six fresh water swamp forests of Karnataka in India, with $\mathrm{H}^{\prime}$ of 2.53, 3.69, 2.46, 4.04, 3.25 and 4.90. Similarly, in the northern forest-savana ecotone of Ghana [38] obtained H' values of 3.02, 0.04 and 0.39 at near-forest ecotone, near-savana ecotone and mid-ecotone. However, when compared with the findings of Kumar [39] in three sites of tropical dry deciduous forest in western India, where H' values of 0.67 - 0.79 were recorded, the H' value of dry deciduous forest (2.96) in PMP is significantly higher. This indicates that diversity and richness in terms of species, and their distribution, is largely dictated by climate and ecological conditions, a view supported by Bello [12].

Table 1. Species richness and diversity in PMP.

\begin{tabular}{ccccc}
\hline Parameter & DMDF & DDF & DF & DHEF \\
\hline Species richness (Jackknife estimator) & 74.00 & 53.61 & 45.54 & 40.75 \\
Shannon-Wiener function (H') & 3.61 & 2.96 & 1.45 & 2.41 \\
Simpson's diversity index (1-D) & 0.96 & 0.92 & 0.50 & 0.84 \\
Shannon evenness (j') (\%) & 83.95 & 74.62 & 38.08 & 65.36 \\
\hline
\end{tabular}

${ }^{*} \mathrm{DMDF}=$ dry mixed deciduous forest, DDF $=$ dry dipterocarp forest, $\mathrm{DF}=$ dry forest, DHEF $=$ dry hill/evergreen forest. 
Species evenness (E) is a measure of equitability of spread. Values obtained were 0.83 in DMDF, 0.74 in DDF, 0.38 in DF and 0.65 in DHEF. The species in DMDF were more abundant, and the percentage of evenness j (\%) was close to 1.0. Therefore, Shannon's evenness (j) shows that DMDF have highest species diversity and DF have the lowest species diversity in PMP. The slope direction influences tree species diversity at different altitudes [40].

\subsection{Floristic Composition}

To assess the species composition and stand structure, the important value index (IVI) was used. No single species clearly dominated in dry mixed deciduous forest (Table 2). In dry mixed deciduous forest, the most abundant species were Shorea obtusa (8.58\% important value index, IVI), Croton roxburghianus (7.34\% IVI), Pittosporum napaulensis (4.83\% IVI). The highest IVI value belonged to the species Shorea obtusa in dry dipterocarp forest whereas Tectona hamiltoniana in dry forest and Vitex canescens in Dry hill or evergreen forest.

Among all forest types, the most frequently occurring species is Techtona hamiltoniana (in dry forest), with 610 individuals recorded with a relative frequency of $17.12 \%$. Due almost solely to its high relative frequency, Techtona hamiltoniana also has the highest species importance value of 54.25. The next most frequently occurrance species and most important species are Vitex canescens (in DHEF) with important values of 29.13 representing by 263 individual trees with relative frequencies of $12.72 \%$. Result of our study suggest that Techtona hamiltoniana is an ecologically important species in Popa Mountain Park. In DMDF, 52.59\% of the relative abundance included 10 common species (13\% of total in DMDF) while $55.45 \%$ of RA (Relative Abandance) included five common species (9\% of total species) in DDF. In DF only one species made up 70.03\% of RA whereas two species made up 52.61\% of RA in DHEF. These findings indicate that the number of species per unit area were high in all investigated forests.

At the family level, it was found that the taxonomic composition of the forests in PMP are different. DMDF was dominated by Dipterocarpaceae, Euphorbiaceae and Combretaceae. Dipterocarpaceae also dominant family in DDF, followed by Verbenaceae, Combreaceae. While, Verbenaceae (mainly Techtona hamiltoniana), Combretaceae and Rhamnaceae were the most common forest tree families in DF. In DHEF, Verbenaceae is the dominant family of trees mostly represented by the Vitec canescens tree and Myrsinaceae and Bixaceae (Table 3).

Dipterocarpaceae family was the family with the highest ecological importance given the IVI value in DMDF. The Dipterocarpaceae with only 3 species ranking $4^{\text {th }}$ in the species-rich family in DMDF, is the most important family based on the IVI values. This highlights that the most species-rich families are not necessarily the most important families based on the IVI values. For example, in DDF, the Dipterocarpaceae with only 3 species ranking $3^{\text {rd }}$ in the species-rich family was the most important family based on the results on IVI. This is due to the high number of individuals and high frequencies. In DF, the highest important value was found in Verbenaceae family, which has 4 species, ranking as the $2^{\text {nd }}$ species-rich family. In DHEF, Verbenaceae family, although with only one species, was the highest ecologically important family according to the IVI value. This is because each species was represented with many individuals.

Verbenaceae, Caesalpiniaceae and Moraceae were observed as species rich families for DMDF, representing 5 species (8\% of the total species) in each family (Table 4). For DDF, the species rich families were Verbenaceae, which possessed 5 species with $9 \%$ of the total species, Anacardiaceae and Rubiaceae which possessed 4 species with $8 \%$ of the total species. The species rich families for DF were found to be Fabaceae and Mimosaceae which were represented by 5 species with $11 \%$ of the total species. In the case of DHEF, the species rich families were Fabaceae and Mimosaceae which processed 3 species with $8 \%$ of the total species.

\subsection{Floristic Homogeneity and Similarity}

An approximate indication of the homogeneity of a stand and of high diversity of tree species can be expressed by frequencies [35]. Species were assigned the frequency classes I, II, III, IV and V using their absolute frequencies $0 \%$ - 20\%, 20\% - 40\%, 40\% - 60\%, 60\% - 80\% and 80\% - 100\%, respectively. If high values are found in frequency classes I/II and low values in frequency classes IV/V, it would indicate a high degree of floristic heterogeneity. If high values were found in frequency classes IV/V and low values in I/II, it indicates constant or similar tree species composition in the area. Frequencies depend on the size of the subplots. The larger the subplots, the higher the number of species that will be found in the higher frequency class. Comparison of frequency diagrams is therefore possible when based on the areas with the same subplot sizes. As shown in Figure 2, 
Table 2. Ten highest species important value index (IVI) of forests in PMP.

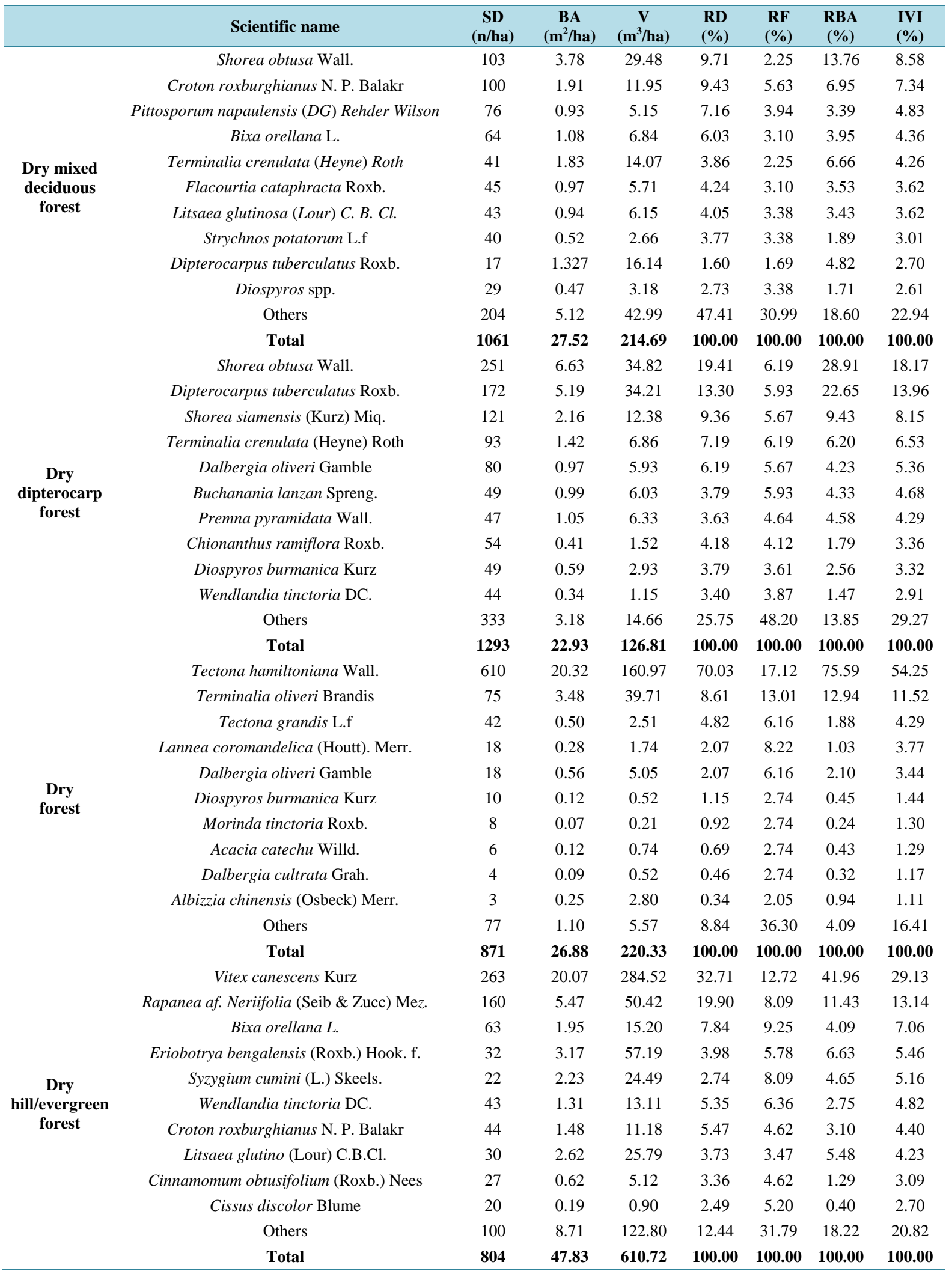

$\mathrm{SD}=$ stand density, $\mathrm{BA}=$ basal area, $\mathrm{Vol}=$ volume, $\mathrm{RD}=$ relative density, $\mathrm{RF}$ = relative frequency, $\mathrm{RBA}=$ relative basal area. 
Table 3. Ten highest family important value index (IVI) of forests in PMP.

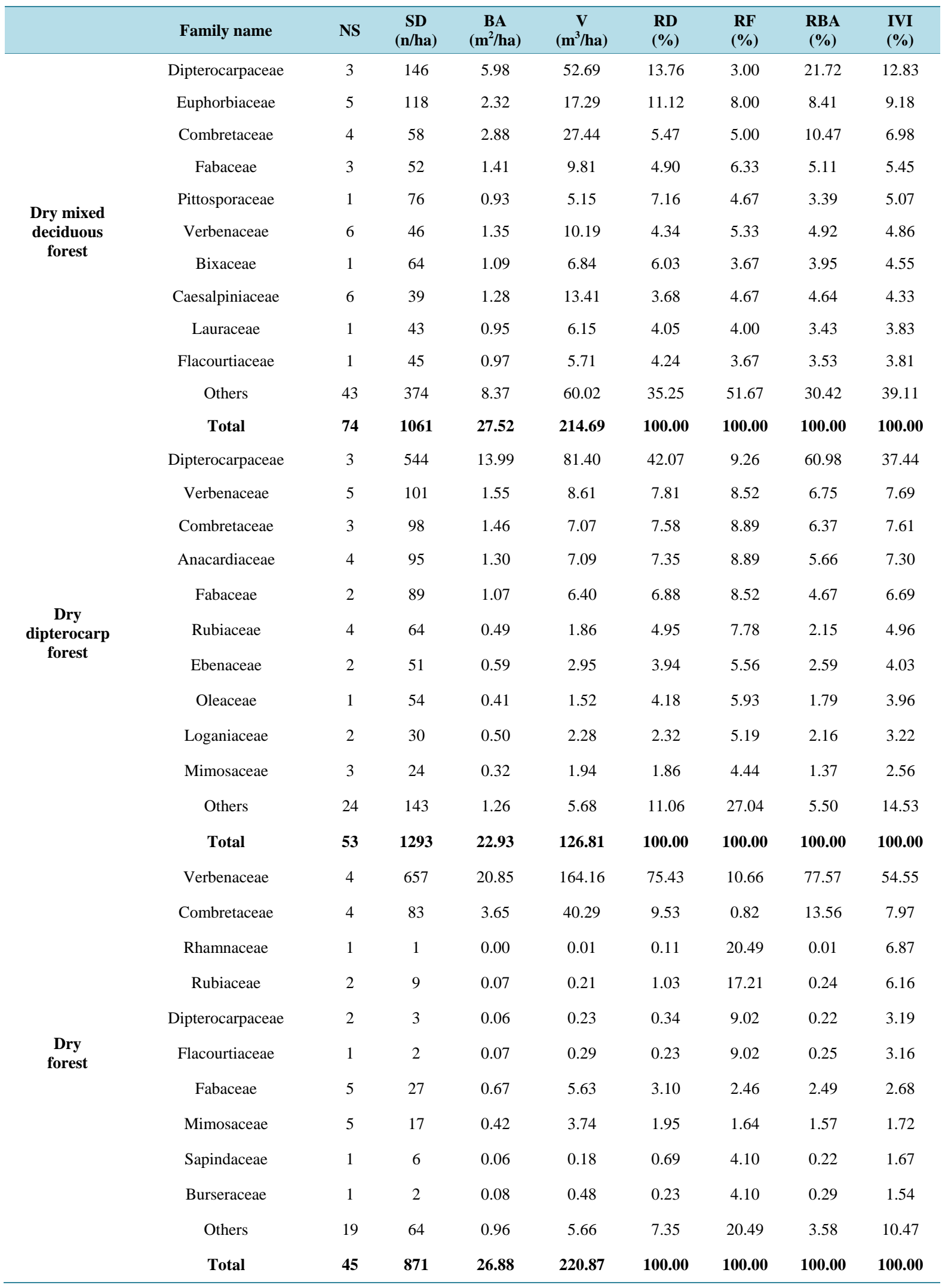




\begin{tabular}{ccccccccccc} 
Continued & & & & & & & & \\
\hline & Verbenaceae & 1 & 263 & 20.07 & 284.52 & 32.71 & 13.25 & 41.96 & 29.31 \\
& Myrsinaceae & 1 & 160 & 5.47 & 50.42 & 19.90 & 8.43 & 11.43 & 13.25 \\
& Bixaceae & 1 & 63 & 1.95 & 15.20 & 7.84 & 9.04 & 4.09 & 6.99 \\
& Euphorbiaceae & 2 & 48 & 3.22 & 35.40 & 5.97 & 7.23 & 6.74 & 6.65 \\
$\begin{array}{c}\text { Dry } \\
\text { hill/evergreen } \\
\text { forest }\end{array}$ & Rosaceae & 1 & 32 & 3.17 & 57.19 & 3.98 & 6.02 & 6.63 & 5.54 \\
& Myrtaceae & 1 & 22 & 2.23 & 24.49 & 2.74 & 8.43 & 4.65 & 5.27 \\
& Rubiaceae & 2 & 45 & 1.35 & 13.23 & 5.60 & 7.23 & 2.82 & 5.21 \\
& Fabaceae & 3 & 39 & 3.06 & 29.86 & 4.85 & 4.22 & 6.39 & 5.15 \\
& Lauraceae & 1 & 27 & 0.62 & 5.12 & 3.36 & 4.82 & 1.29 & 3.16 \\
& Vitaceae & 1 & 20 & 0.19 & 0.90 & 2.49 & 5.42 & 0.40 & 2.77 \\
& Others & 26 & 85 & 6.51 & 94.40 & 10.57 & 25.90 & 13.60 & 16.69 \\
& Total & $\mathbf{4 0}$ & $\mathbf{8 0 4}$ & $\mathbf{4 7 . 8 3}$ & $\mathbf{6 1 0 . 7 1}$ & $\mathbf{1 0 0 . 0 0}$ & $\mathbf{1 0 0 . 0 0}$ & $\mathbf{1 0 0 . 0 0}$ & $\mathbf{1 0 0 . 0 0}$ \\
\hline
\end{tabular}

NS = number of species, $\mathrm{SD}=$ stand density, $\mathrm{BA}=$ basal area, $\mathrm{Vol}=$ volume, $\mathrm{RD}=$ relative density, $\mathrm{RF}=$ relative frequency, $\mathrm{RBA}=$ relative basal area.

Table 4. Floristic similarity of forest types in PMP.

\begin{tabular}{ccccc}
\hline \multirow{2}{*}{ Forest stand } & \multicolumn{2}{c}{ Families similarity } & \multicolumn{2}{c}{ Species similarity } \\
\cline { 2 - 5 } & Sorencen's index (\%) & Jaccard index (\%) & Sorencen's index (\%) & Jaccard index (\%) \\
\hline DMDF and DDF & 86.67 & 79.79 & 64.57 & 67.41 \\
DMDF and DF & 64.29 & 59.55 & 45.38 & 54.49 \\
DMDF and DHEF & 77.42 & 77.73 & 52.63 & 65.54 \\
DDF and DF & 72.00 & 71.67 & 46.94 & 57.74 \\
DDF and DHEF & 64.29 & 77.67 & 43.01 & 53.44 \\
DF and DHEF & 53.85 & 75.87 & 25.88 & \\
\hline
\end{tabular}

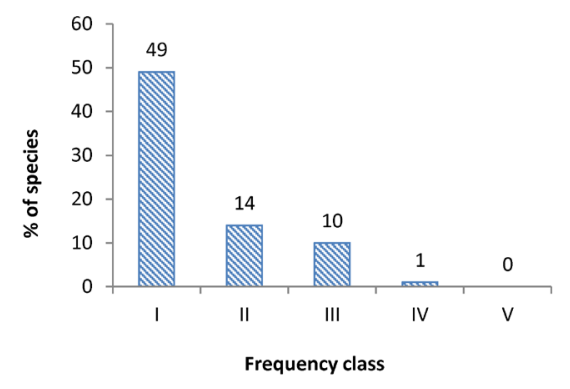

(a)

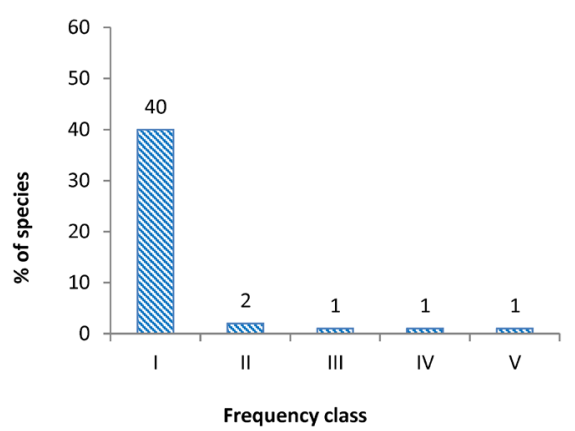

(c)

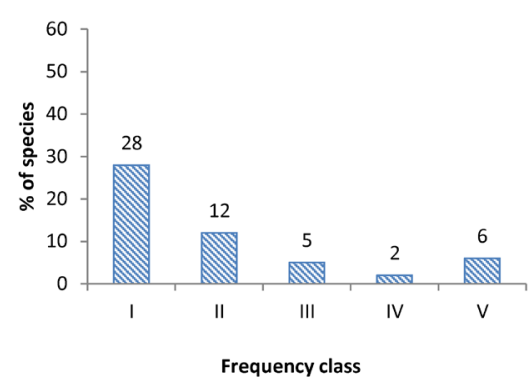

(b)

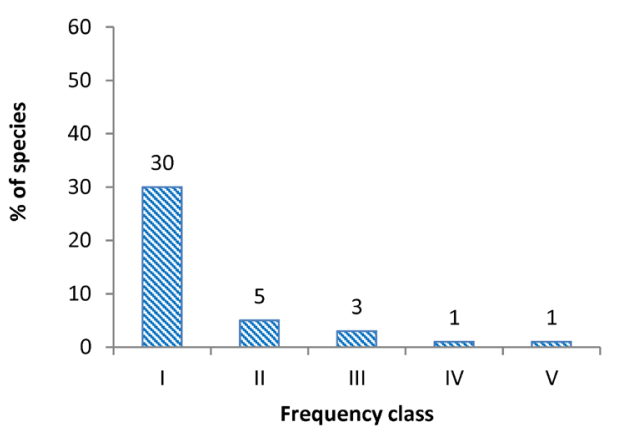

(d)

Figure 2. Frequency diagram of the dry mixed deciduous forest (a); dry dipterocarp forest (b); dry forest (c) and dry hill or dry evergreen forest (d). 
frequency values in I/II classes are higher than in IV/V classes indicating that all forests in PMP have a high degree of floristic heterogeneity and high diversity of species.

The similarities in species composition between the forests are presented in Table 4. Similarity indices range from $0.0-1.0$, corresponding to a $0 \%-100 \%$ similarity between any two plant communities. Coefficients of similarity of species composition (Sorensen's index) between DMDF and DDF showed higher values. Their respective vegetation communities share $86 \%$ of the species between the DMDF and DDF. When the forest stands were paired and compared against each other, only DMDF and DDF showed a highly similar species composition. It was found that 46 species were common between the DMDF and DDF, 27 species between DMDF and DF, 30 species between DMDF and DHEF, 23 species between DDF and TDF, 20 species between DDF and DHEF and 11 species between DF and DHEF. Likewise, high similarity values of the family were found in DMDF and DDF.

\subsection{Stand Structure}

It was found that dry evergreen forest has the highest mean diameter at breast height (DBH) $24.03 \mathrm{~cm}$ and dry dipterocarp forest has the lowest mean DBH, $11 \mathrm{~cm}$ (Table 5). Mean tree density (DBH $\geq 5 \mathrm{~cm}$ ) of the various forest stands was DMDF, 1061 trees ha ${ }^{-1}$, DDF, 1293 trees ha ${ }^{-1}$, DF, 871 trees ha ${ }^{-1}$ and DHEF, 804 trees ha ${ }^{-1}$. The standing volumes were $214.69 \mathrm{~m}^{3} \cdot \mathrm{ha}^{-1}$ in DMDF, $126.81 \mathrm{~m}^{3} \cdot \mathrm{ha}^{-1}$ in DDF, $220.33 \mathrm{~m}^{3} \cdot \mathrm{ha}^{-1}$ in DF and 610.72 $\mathrm{m}^{3} \cdot \mathrm{ha}^{-1}$ in DHEF. The mean volume of DHEF was highly significantly different ( $\left.\mathrm{p}>0.01\right)$ among the forests in PMP. However, the stand density was the lowest in DHEF while the standing volume strongly suggestion that the trees in DHEF are more mature than other forests. In term of species, Shorea obtusa made up the highest standing volume $\left(29.48 \mathrm{~m}^{3} \cdot \mathrm{ha}^{-1}\right)$ in DMDF and $\left(34.82 \mathrm{~m}^{3} \cdot \mathrm{ha}^{-1}\right)$ in DDF while Tectona hamiltoniana was the highest $\left(160.97 \mathrm{~m}^{3} \cdot \mathrm{ha}^{-1}\right)$ in DF and Vites canescen $\left(284.52 \mathrm{~m}^{3} \cdot \mathrm{ha}^{-1}\right)$ in DHEF.

Diameter frequency distributions provide a useful substitute for development trends of the stands [35] and help to evaluate potential forest sustainability [41]. For all forest types in PMP, it was found that increasing tree size classes results in drastically decreased species richness (SR), density (D) and diversity (H') (Table 6). Shannon-Wiener diversity Index (H') showed that the smaller DBH size classes have the higher diversity. The study found that lower size classes; $5-10 \mathrm{~cm}$ and $10-15 \mathrm{~cm}$, contributed more than $50 \%$ of total tree density in the investigated forests. As well, the lowest size class, DBH $5-10 \mathrm{~cm}$, possessed the highest species richness in all of the forests. In the $5-10 \mathrm{~cm}$ DBH size class, we found 55 out of 74 species in DMDF, 47 out of 53 species in DDF, 32 out of 45 species in DF and 20 out of 40 species in DH. The higher numbers of species were found in the lower size class in all forest types.

The findings in this study indicate that, where tree density is generally higher in small DBH classes compared to large DBH classes, this is a secondary forest characteristic. In all the forest stands, the greater numbers of trees were observed in the lowest diameter class $(5-10 \mathrm{~cm})$. This indicates that the density of smaller trees in a stand is sufficient to replace the current population of larger tree. The diameter distribution of the trees followed the inverse J-shape pattern (Figure 3(a)). This pattern indicated that stands are developing and regeneration is occurring in the forest indicating a high potential for species substitution when mature trees in the dominant species die.

The diameter classes $15.1-20 \mathrm{~cm}, 10.1-15 \mathrm{~cm}, 15.1$ - $20 \mathrm{~cm}$ and 25.1 - $30 \mathrm{~cm}$ occupied the largest basal

Table 5. Characteristics of different forest types in PMP.

\begin{tabular}{|c|c|c|c|c|}
\hline Parameter & DMDF & DDF & DF & DHEF \\
\hline Mean DBH (cm) & 17.50 & 11.00 & 13.34 & 24.03 \\
\hline Mean Ht (m) & 13.80 & 6.69 & 7.38 & 13.20 \\
\hline $\mathrm{BA}\left(\mathrm{m}^{2} \cdot \mathrm{ha}^{-1}\right)$ & 27.50 & 22.93 & 26.87 & 47.80 \\
\hline $\operatorname{Vol}\left(\mathrm{m}^{3} \cdot \mathrm{ha}^{-1}\right)$ & 214.69 & 126.80 & 220.33 & 610.71 \\
\hline Stand density (trees ha ${ }^{-1}$ ) & 1061 & 1293 & 871 & 804 \\
\hline No. of families & 33 & 27 & 23 & 29 \\
\hline No. of species & 74 & 53 & 45 & 40 \\
\hline
\end{tabular}

${ }^{*}$ DMDF = dry mixed deciduous forest, DDF= dry dipterocarp forest, DF= dry forest, DHEF = dry hill/evergreen forest, DBH $=$ diameter at breast height, $\mathrm{Ht}=$ height, $\mathrm{BA}$ = basal area, $\mathrm{Vol}=$ volume. 
area per ha in DMDF, DDF, DF and DHEF, respectively (Figure 3(b)). No stems in diameter classes $55.1 \mathrm{~cm}$ were found in DDF and no $70.1 \mathrm{~cm}$ diameter stems were found in DMDF and DF. Large diameter size classes of tree were rarely found in most of the forests in PMP. This might be due to over-cutting of trees (for firewood) from the surrounding area. In DHEF, large tree with stem diameters up to the $95.1-100 \mathrm{~cm}$ DBH class. It is therefore probable that less human disturbance in DHEF occurred above $1000 \mathrm{~m}$, being less accessible.

Table 6. Frequency of species distributed DBH class and it Shanmon-Wiener (H') in investigated forests in PMP.

\begin{tabular}{|c|c|c|c|c|c|c|c|c|c|c|c|c|}
\hline \multirow{2}{*}{$\begin{array}{c}\text { DBH } \\
\text { class }(\mathrm{cm})\end{array}$} & \multicolumn{3}{|c|}{ DMDF } & \multicolumn{3}{|c|}{ DDF } & \multicolumn{3}{|c|}{$\mathrm{DF}$} & \multicolumn{3}{|c|}{ DHEF } \\
\hline & SR & $\mathrm{D}$ & $\mathrm{H}^{\prime}$ & SR & $\mathrm{D}$ & $\mathrm{H}^{\prime}$ & SR & $\mathrm{D}$ & $\mathrm{H}^{\prime}$ & SR & $\mathrm{D}$ & $\mathrm{H}^{\prime}$ \\
\hline $5-10$ & 55 & 348 & 0.37 & 47 & 565 & 0.36 & 32 & 250 & 0.36 & 20 & 151 & 0.31 \\
\hline 10.1 - 15 & 52 & 292 & 0.36 & 40 & 371 & 0.36 & 22 & 240 & 0.36 & 19 & 174 & 0.33 \\
\hline 15.1 - 20 & 40 & 158 & 0.28 & 20 & 157 & 0.26 & 18 & 144 & 0.30 & 21 & 144 & 0.31 \\
\hline $20.1-25$ & 44 & 121 & 0.25 & 15 & 98 & 0.20 & 8 & 89 & 0.23 & 16 & 90 & 0.25 \\
\hline $25.1-30$ & 29 & 66 & 0.17 & 10 & 62 & 0.15 & 9 & 56 & 0.18 & 16 & 75 & 0.22 \\
\hline 30.1 - 35 & 20 & 39 & 0.12 & 4 & 26 & 0.08 & 6 & 34 & 0.13 & 11 & 44 & 0.16 \\
\hline $35.1-40$ & 13 & 19 & 0.07 & 5 & 11 & 0.04 & 3 & 21 & 0.09 & 10 & 32 & 0.13 \\
\hline $40.1-45$ & 7 & 8 & 0.04 & 1 & 1 & 0.01 & 3 & 15 & 0.07 & 11 & 26 & 0.11 \\
\hline $45.1-50$ & 1 & 1 & 0.01 & 0 & 0 & 0.00 & 2 & 13 & 0.06 & 4 & 9 & 0.05 \\
\hline $50.1-55$ & 4 & 4 & 0.02 & 2 & 2 & 0.01 & 2 & 4 & 0.02 & 6 & 20 & 0.09 \\
\hline $55.1-60$ & 2 & 4 & 0.02 & - & - & - & 1 & 2 & 0.01 & 5 & 10 & 0.05 \\
\hline $60.1-65$ & - & - & - & - & - & - & 1 & 2 & 0.01 & 3 & 5 & 0.03 \\
\hline $65.1-70$ & 1 & 1 & 0.01 & - & - & - & 1 & 1 & 0.01 & 3 & 8 & 0.05 \\
\hline 70.1 - 75 & - & - & - & - & - & - & - & - & - & 2 & 2 & 0.01 \\
\hline 75.1 - 80 & - & - & - & - & - & - & - & - & - & 2 & 5 & 0.03 \\
\hline 80.1 - 85 & - & - & - & - & - & - & - & - & - & 2 & 2 & 0.01 \\
\hline 85.1 - 90 & - & - & - & - & - & - & - & - & - & 1 & 3 & 0.02 \\
\hline 90.1 - 95 & - & - & - & - & - & - & - & - & - & 2 & 3 & 0.02 \\
\hline $95.1-100$ & - & - & - & - & - & - & - & - & - & 1 & 1 & 0.01 \\
\hline
\end{tabular}

“SR = species richness, $\mathrm{D}$ = density, H' = Shannon-Wiener diversity index.

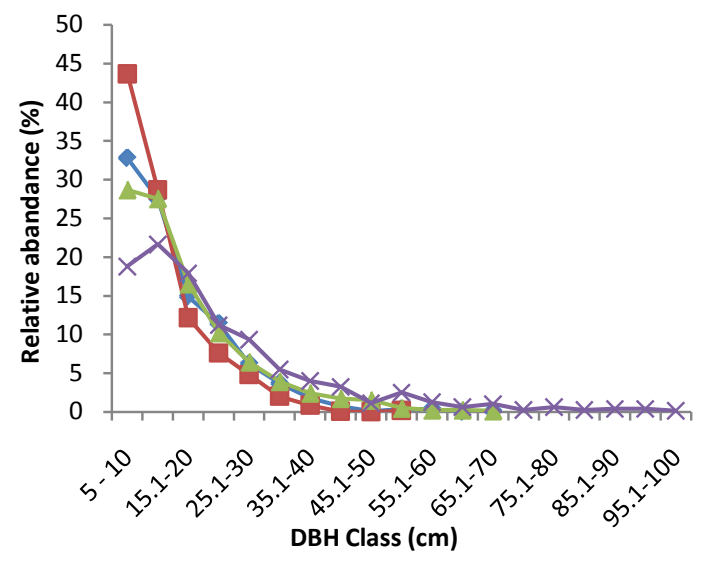

(a)

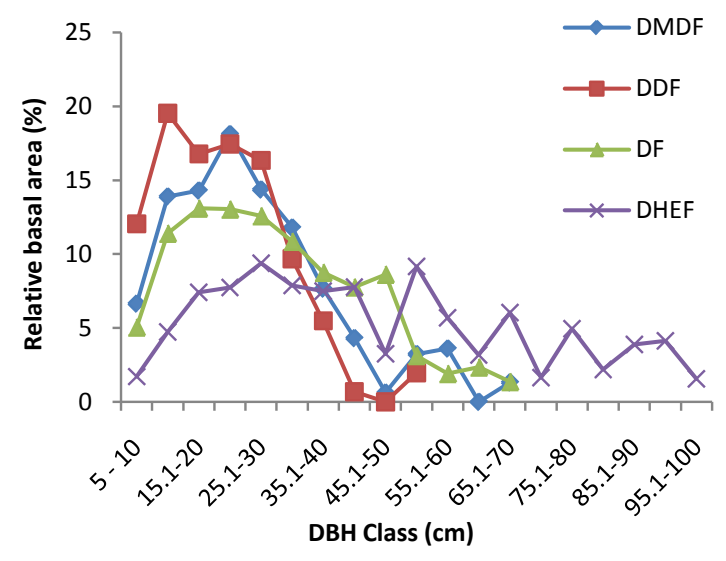

(b)

Figure 3. Relative abundance (a) and relative basal area (b) in relation to diameter classes in the investigated forest in PMP. 


\subsection{Species-Area Curve}

Figure 4 shows species-area-curves. It can be seen DMDF has a greater richness of trees of stem diameter $\geq 5$ $\mathrm{cm}$ than the other forest types while DDF has intermediate richness levels. However, DF and DHEF has similar species richness but lower than DMDF and DDF. In this study, the species-area curves were drawn based on trees with height $\geq 1.3 \mathrm{~m}$ and $\mathrm{DBH} \geq 5 \mathrm{~cm}$, and the total survey areas were one hectare in each forest. Lamprecht [35] suggested that a stock with $\mathrm{DBH}>10 \mathrm{~cm}$ is generally adequate to draw species-area curves. He also suggested that the species-area curve is the best criterion for determining a minimal plot size needed to survey a community adequately. The pattern of the DMDF curve increases significantly up to the point of 0.40 ha, after which the increase is much more gradual with the increment of the number of species remaining below $10 \%$. Similarly, in DDF new species were found in areas up 0.48 ha after which the increment remained below $10 \%$ from 0.48 ha up. Likewise, the pattern of DF curve and DHEF curve went up gradually and then became constant from 0.64 ha and 0.48 , respectively. The minimum representative area would be reached if the number of species increases by less than $10 \%$ when the expansion of sampling area is $10 \%$ [42]. According to the species-area-curve, one ha sample size represented the minimum area for each forest type since there were only minimal numbers of new species discovered.

\section{Discussion}

The species-area curves showed that sampling was adequate in all forests to provide representative estimates of species diversity in PMP. The number of species increased substantially up to the point of 0.40 ha in DMDF, 0.48 ha in DDF, 0.64 ha in DF and 0.48 ha in DHEF. The increment of species was then less than $10 \%$ until the sampling area reached 1.00 ha. According to Cain and Castro [41], the minimum representative area will be reached if the number of species increases by less than $10 \%$ when expansion of sampling area is $10 \%$. Therefore 1 ha sample plot is represented for each of forest type.

It was found that dry hill or evergreen forest (DHEF) has the highest mean diameter at breast height (DBH) $24.03 \mathrm{~cm}$ and highest volume $\left(610.72 \mathrm{~m}^{3} \cdot \mathrm{ha}^{-1}\right)$ while stand density $\left(804\right.$ trees $\left.\mathrm{ha}^{-1}\right)$ was the lowest among forest types showing that the DHEF is more mature than other forest types in PMP with less human disturbance in the area. This may be due to the distance from the surrounding settled areas as DHEF was found in high elevation and more remote from the park boundary. The highest stand density (1293 trees ha $\left.{ }^{-1}\right)$ was found in dry deciduous forest (DDF) with lowest standing volume $\left(126.80 \mathrm{~m}^{3} \cdot \mathrm{ha}^{-1}\right)$ signifying that DDF has human disturbance and large trees had been harvested prior to data collection, probably due to nearness of roads and ease of access. DDF was found between $400 \mathrm{~m}-700 \mathrm{~m}$ asl and the park circular road was close to the DDF. Forest cover loss was more severe in the areas near roads and therefore the likelihood of encroachment by local communities is high in the accessible forest at low elevations [23].

The diameter distribution of trees was investigated in order to know the population structure of the forest. In all forests, higher species richness and diversity were found in small DBH classes (Table 5). Tree density was

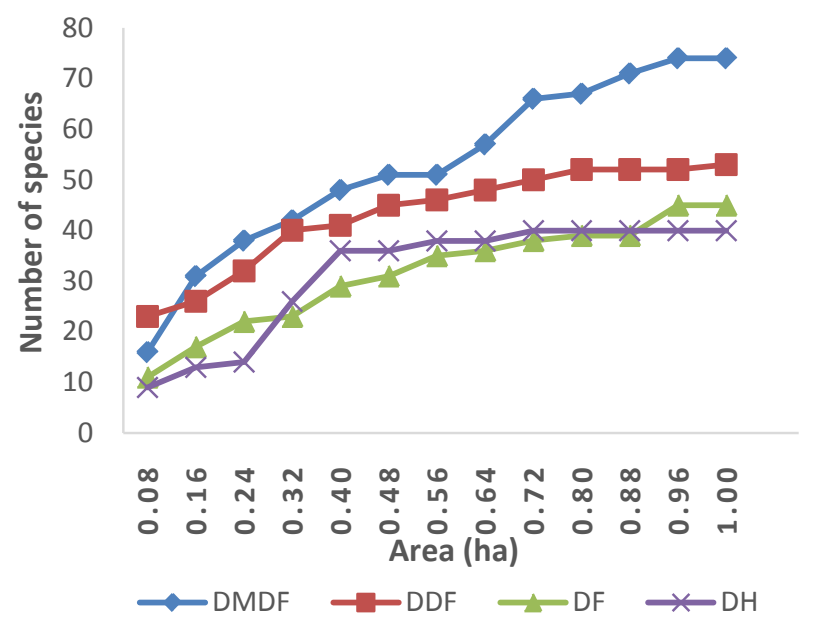

Figure 4. Species area curve for all trees $(\mathrm{DBH} \geq 5 \mathrm{~cm})$ in PMP. 
also higher in the small DBH classes indicating that small tree were in sufficient numbers to replace mature trees when necessary. Diameter distribution curves show the pattern of population structure. The inverse J shaped curves for the entire investigated stands show that the stands have a growing population structure. However, the mean DBH in all forest is small; $17.50 \mathrm{~cm}$ in DMDF, $11.00 \mathrm{~cm}$ in DDF, $13.34 \mathrm{~cm}$ in DF and $24.03 \mathrm{~cm}$ in DHEF. These may be the actual lower thresholds of $\mathrm{DBH}$ in the inventory. This study however measured all trees of $\mathrm{DBH} \geq 5 \mathrm{~cm}$. The highest tree density was found in the DBH classes $5-10 \mathrm{~cm}$ and $10-15 \mathrm{~cm}$ which contribute more than $50 \%$ of total tree density. From the shape of the inversed $\mathrm{J}$ shape curve of relative abundance over $\mathrm{DBH}$ of small DBH trees, we can conclude that it is a common pattern of stand structure of the forests in logged and deforested areas.

Stand structures of the DHEF suggested that this forest is less disturbed because many large trees were still found in this forest compared to the other forests. This may be due to the fact that DHEF is located at high elevations and remote from the park boundaries and human habitation. These findings support Htun [23] whose findings were that forest cover loss was high in areas close to park boundaries and roads and low in remote and less accessible areas.

Patrolling is the main method for forest conservation in the PMP. Limited infrastructure however made conservation activities difficult. In addition, budgets for conservation activities were insufficient. Total government budget for conservation of PMP for 2007-2008 was US \$115,000, of which government staff salaries consumed $83 \%$, and much of the remainder was used for administration and maintenance rather than for conservation activities [22]. Effective conservation of this important park requires more budget as well as infrastructure. With no alternative funding source, it is difficult to maintain and conserve current forest conditions in PMP. Our findings indicate that forests in the PMP are rich in species diversity but stand structures of these forests are similar to that of degraded forests. Therefore, it is possible to conclude that forest conservation in the PMP is still ineffective and there is critical need to control human disturbance. Future study on drivers of deforestation and forest degradation and how to address these drivers would provide the needed information for effective conservation of the PMP.

\section{Conclusions}

This study focused on analyzing tree species diversity and stand structures in the Popa Mountain Park in Myanmar. Forest inventory was conducted in four forest types, namely dry mixed deciduous forest, dry dipterocarp forest, dry forest and dry hill/evergreen forest. We used Jackknife estimator, Simpson’s index, Shannon's index and Evenness indices for data analysis. The distribution of trees in all forest types in PMP displays an inverse J distribution where stem frequencies decrease with the increase in $\mathrm{DBH}$, indicating stable condition of naturally regenerated trees in the study sites. The study also shows that all forests in PMP have a high degree of floristic heterogeneity. In terms of tree species in individual forest, the number of species found in each of the forests does not vary much among DDF, DF and DHEF. However, the total of 74 species in DMDF is significantly greater than the other forests. The basal area for the DMDF along with the DDF and DF was significantly lower than that of DHEF. On the contrary, the density of trees was significantly lower in DHEF than that in other forest types. But the density of trees in the largest size class was higher in DHEF than that in other forest types. The occurrence of high basal area and high density of trees in the largest size class suggested that DHEF was less disturbed than other forests in the PMP. DF and DMDF had a relatively low proportion of trees in larger size classes due to population pressure and timber harvesting. Large trees with DBH greater than $55 \mathrm{~cm}$ in DDF were harvested but there were plentiful trees with small DBH, suggesting that natural regeneration capacity for this forest is good.

Our study findings suggested that PMP was rich in terms of tree species but many large trees in accessible forests were harvested except in dry hill or evergreen forest, where large trees still remained in the forests. This was due to less population pressure and limited access to this forest. Considering the structural diversity and the substantially lower density observed in large DBH classes, the PMP has not been effectively protected although it is a designated protected area by the government. Lack of effective mechanisms and funding may have contributed to this failure. Management interventions that take into account the need of local people, tree diversity, and transition of forest stand structures would protect this PMP. Law enforcement mechanism is also important to ensure that government regulation and policies regarding protected area are not violated or punished otherwise. In addition, it is necessary to clarify the land use policy and to cooperate with local communities to main- 
tain the integrity of designated protected areas. It is also fairly necessary to provide incentives to forest-dependent communities for their activities to protect this protected area. Forest-dependent communities should be allowed to participate in all decision making processes for sound management of protected areas. Implementing activities on the ground such as restoring degraded forests and protecting the park require participation from both government agency and local communities. Effective forest restoration strategies need to know the condition of the degree of forest degradation, tree species composition, and stand structures. Information provided in our study is useful for introducing future policy interventions, conservation measures, and forest restoration in Popa Mountain Park. Future study on long term monitoring of forest composition change would provide additional information on the pattern of structural changes useful for revising policy intervention and conservation system in PMP.

\section{Acknowledgements}

We would like to appreciate the Forest Department of Myanmar for providing assistance during the data collection in Myanmar. This study was partially supported by a grant-in-aid for Scientific Research Category A (No. 24252002) from the Ministry of Education, Culture, Sports, Science and Technology of Japan.

\section{References}

[1] FAO (2010) Forests and Climate Change in the Asia-Pacific Region. Italy, 108.

[2] Farhadi, P., Soosani, J., Alijani, V. and Adeli, K. (2013) Comparison of the Quercus brantii and Pyrus glabra Boiss Species Structure in Zagros Forests (Case Study: Ghalehgol Forest, Khoramabad City, Iran). International Journal of Biological Sciences, 3, 210-217.

[3] Swaine, M.D. and Hall, J.B. (1983) Early Succession on Cleared Forest Land in Ghana. Journal of Ecology, 71, 601-627. http://dx.doi.org/10.2307/2259737

[4] Singh, J.S., Sahu, P.K. and Sagar, R. (2008) Tropical Forest Structure and Diversity in Relation to Altitude and Disturbance in a Biosphere Reserve in Central India. Applied Vegetation Science, 11, 461-470. http://dx.doi.org/10.3170/2008-7-18537

[5] FAO (2009) State of World's Forests. FAO (Food and Agriculture Organization of the United Nations), Italy, 168.

[6] Taylor, D., Hamilton, A.C., Lewis, S.L. and Nantale, G. (2008) Thirty-Eight Years of Change in a Tropical Forest: Plot Data from Mpanga Forest Reserve, Uganda. African Journal of Ecology, 46, 655-667. http://dx.doi.org/10.1111/j.1365-2028.2008.00955.x

[7] Thapa, S. and Chapman, D.S. (2010) Impacts of Resource Extraction on Forest Structure and Diversity in Bardia National Park, Nepal. Forest Ecology and Management, 259, 641-649. http://dx.doi.org/10.1016/j.foreco.2009.11.023

[8] FAO (2010) Global Forest Resources Assessment 2010. Main Report, Food and Agriculture Organization, Italy, 340.

[9] Thomas, C.D., Cameron, A., Green, R.E., Bakkenes, M., Beaumont, L.J., Collingham, Y.C., Erasmus, B.F.N., De Siqueira, M.F., Grainger, A., Hannah, L., Hughes, L., Huntley, B., Van Jaarsveld, A.S., Midgley, G.F., Miles, L., OrtegaHuerta, M.A., Peterson, A.T., Phillips, O.L. and Williams, S.E. (2004) Extinction Risk from Climate Change. Nature, 427, 145-148. http://dx.doi.org/10.1038/nature02121

[10] Sagar, R., Raghubanshi, A. and Singh, J. (2003) Tree Species Composition, Dispersion and Diversity along a Disturbance Gradient in a Dry Tropical Forest Region of India. Forest Ecology and Management, 186, 61-71. http://dx.doi.org/10.1016/S0378-1127(03)00235-4

[11] FAO (2003) Tropical Secondary Forest Management in Africa: Reality and Perspectives. In: Workshop on Tropical Secondary Forest Management in Africa, Food and Agriculture Organization, Rome.

[12] Bello, A.G., Isah, A.D. and Ahmad, B. (2013) Tree Species Diversity Analysis of Kogo Forest Reserve in NorthWestern Nigeria. International Journal of Plant, Animal and Environmental Sciences, 3, 189-196.

[13] Huang, W., Pohjonen, V., Johansson, S., Nashanda, M., Katigula, M.I. and Luukkanen, O. (2003) Species Diversity, Forest Structure and Species Composition in Tanzanian Tropical Forests. Forest Ecology and Management, 173, 11-24. http://dx.doi.org/10.1016/S0378-1127(01)00820-9

[14] Aung, M., Khaing Swe, K., Oo, T., Kyaw Moe, K., Leimgruber, P., Allendorf, T., Duncan, C. and Wemmer, C. (2004) The Environmental History of Chatthin Wildlife Sanctuary, a Protected Area in Myanmar (Burma). Journal of Environmental Management, 72, 205-216. http://dx.doi.org/10.1016/j.jenvman.2004.04.013

[15] Allendorf, T., Swe, K.K., Oo, T., Htut, Y.E., Aung, M., Allendorf, K., Hayek, L., Leimgruber, P. and Wemmer, C. (2006) Community Attitudes toward Three Protected Areas in Upper Myanmar (Burma). Environmental Conservation, 33, 344-352. http://dx.doi.org/10.1017/S0376892906003389 
[16] Andam, K.S., Ferraro, P.J., Pfaff, A., Sanchez-Azofeifa, G.A. and Robalino, J. (2008) Measuring the Effectiveness of Protected Area Networks in Reducing Deforestation. Proceedings of the National Academy of Sciences of the United States of America, 105, 16089-16094. http://dx.doi.org/10.1073/pnas.0800437105

[17] Kyi, Y.Y. (1992) Preliminary Report on Vegetation and Flora of Mount Popa. Yezin, Myanmar, 1-4.

[18] Kyi, Y.Y. and Moe, A.Z. (1997) Plant Biodiversity of Mount Popa (Part I). Yezin, Myanmar, 21.

[19] Suratman, M.N. (2012) Tree Species Diversity and Forest Stand Structure of Pahang National Park, Malaysia. In: Lameed, G.A., Ed., Biodiversity Enrichment in a Diverse World, 473-492.

[20] Htun, N.Z., Mizoue, N. and Yoshida, S. (2011) Classifying Tropical Deciduous Vegetation: A Comparison of Multiple Approaches in Popa Mountain Park, Myanmar. International Journal of Remote Sensing, 32, 8935-8948. http://dx.doi.org/10.1080/01431161.2010.531779

[21] FD (1981) Proposed Popa Mountain Park Master Plan 1982-1984. UNDP/FAO, Forest Department, Nature Conservation National Park Project, Vol. 43, FD (Forest Department): BUR/80/006, Rangoon.

[22] Htun, N.Z., Mizoue, N., Kajisa, T. and Yoshida, S. (2010) Deforestation and Forest Degradation as Measures of Popa Mountain Park (Myanmar) Effectiveness. Environmental Conservation, 36, 218-224. http://dx.doi.org/10.1017/S0376892909990415

[23] Htun, N.Z., Mizoue, N. and Yoshida, S. (2013) Changes in Determinants of Deforestation and Forest Degradation in Popa Mountain Park, Central Myanmar. Environmental Management, 51, 423-434. http://dx.doi.org/10.1007/s00267-012-9968-5

[24] Kress, W.J., Defilipps, R.A., Farr, E. and Kyi, Y.Y. (2003) A Checklist of the Trees, Shrubs, Herbs and Climbers of Myanmar.

[25] Heltshe, J.F. and Forrester, N.E. (1983) Estimating Species Richness Using the Jackknife. Biometrics, 39, 1-11. http://dx.doi.org/10.2307/2530802

[26] Simpson, E.H. (1949) Measurement of Diversity. Nature, 163, 688.

[27] Shannon, C.E. and Weaver, W.J. (1949) The Mathematical Theory of Communication. University of Illinois Press, Urbana, 117 p.

[28] Magurran, A.E. (1988) Ecological Diversity and Its Measurement. Croom Helm, London, 178.

[29] Curits, J.T. and McIntosh, R.P. (1951) An Upland Forest Continuum in the Prairie-Forest Border Region on Wisconsin. Ecology, 32, 476-496. http://dx.doi.org/10.2307/1931725

[30] De, A. (2007) Patterns of Plant Species Diversity in the Forest Corridor of Rajaji-Corbett National Parks, Uttaranchal, India. Current Science, 92, 90-93.

[31] Phillips, O.L. and Gentry, A.H. (1994) Increasing Turnover through Time in Tropical Forests. Science, 263, $954-958$. http://dx.doi.org/10.1126/science.263.5149.954

[32] Gillespie, T.W., Keppel, G., Pau, S., Price, J.P., Jaffré, T. and O’Neill, K. (2013) Scaling Species Richness and Endemism of Tropical Dry Forests on Oceanic Islands. Diversity and Distributions, 19, 896-906. http://dx.doi.org/10.1111/ddi.12036

[33] Homeier, J., Breckle, S., Sven, G., Rollenbeck, R.T. and Leuschner, C. (2010) Tree Diversity, Forest Structure and Productivity along Altitudinal and Topographical Gradients in a Species-Rich Ecuadorian Montane Rain Forest. Biotropica, 42, 140-148. http://dx.doi.org/10.1111/j.1744-7429.2009.00547.x

[34] Kitamura, S., Suzuki, S., Yumoto, T., Chuailua, P., Plongmai, K., Poonswad, P., Noma, N., Maruhashi, T. and Suckasam, C. (2005) A Botanical Inventory of a Tropical Seasonal Forest in Khao Yai National Park, Thailand: Implications for Fruit-Frugivore Interactions. Biodiversity \& Conservation, 14, 1241-1261. http://dx.doi.org/10.1007/s10531-004-7848-x

[35] Lamprecht, H. (1989) Silviculture in the Tropics: Tropical Forest Ecosystems and Their Species-Possibilities and Methods for Their Long-Term Utilization. Deutsche Gesellschaft Fur Technische Zusammenarbeit (GTZ) GmbH, Eschborn, 296.

[36] Kessler, M., Keßler, P.J.A., Gradstein, S.R., Bach, K., Schmull, M. and Pitopang, R. (2005) Tree Diversity in Primary Forest and Different Land Use Systems in Central Sulawesi, Indonesia. Biodiversity \& Conservation, 14, 547-560. http://dx.doi.org/10.1007/s10531-004-3914-7

[37] Bhat, P.R. and Kaveriappa, K.M. (2009) Ecological Studies on Myristica Swamp Forests of Uttara Kannada, Karnataka, India. Tropical Ecology, 50, 329-337.

[38] Attua, E.M. and Pabi, O. (2013) Tree Species Composition, Richness and Diversity in the Northern Forest-Savanna Ecotone of Ghana. Journal of Applied Biosciences, 69, 5437-5448. http://dx.doi.org/10.4314/jab.v69i0.95069

[39] Kumar, J.I.N., Kumar, R.N., Bhoi, R.K. and Sajish, P.R. (2010) Tree Species Diversity and Soil Nutrient Status in 
Three Sites of Tropical Dry Deciduous Forest of Western India. Tropical Ecology, 51, 273-279.

[40] Tian, C.C., Jiang, X.L., Peng, H., Fan, P.F. and Zhou, S.B. (2007) Tree Species Diversity and Structure Characters in the Habitats of Black-Crested Gibbons (Nomascus concolor). Acta Ecologica Sinica, 27, 4002-4010. http://dx.doi.org/10.1016/S1872-2032(07)60089-4

[41] Rubin, B.D., Manion, P.D. and Faber-Langendoen, D. (2006) Diameter Distributions and Structural Sustainability in Forests. Forest Ecology and Management, 222, 427-438. http://dx.doi.org/10.1016/j.foreco.2005.10.049

[42] Cain, S.A. and de Oliviera Castro, G.M. (1959) Manual of Vegetative Analysis. 325 p. 
Scientific Research Publishing (SCIRP) is one of the largest Open Access journal publishers. It is currently publishing more than 200 open access, online, peer-reviewed journals covering a wide range of academic disciplines. SCIRP serves the worldwide academic communities and contributes to the progress and application of science with its publication.

Other selected journals from SCIRP are listed as below. Submit your manuscript to us via either submit@scirp.org or Online Submission Portal.
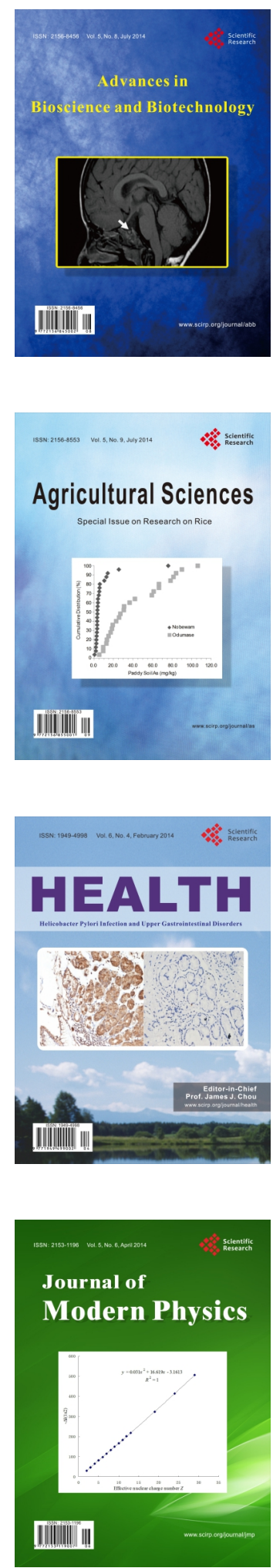
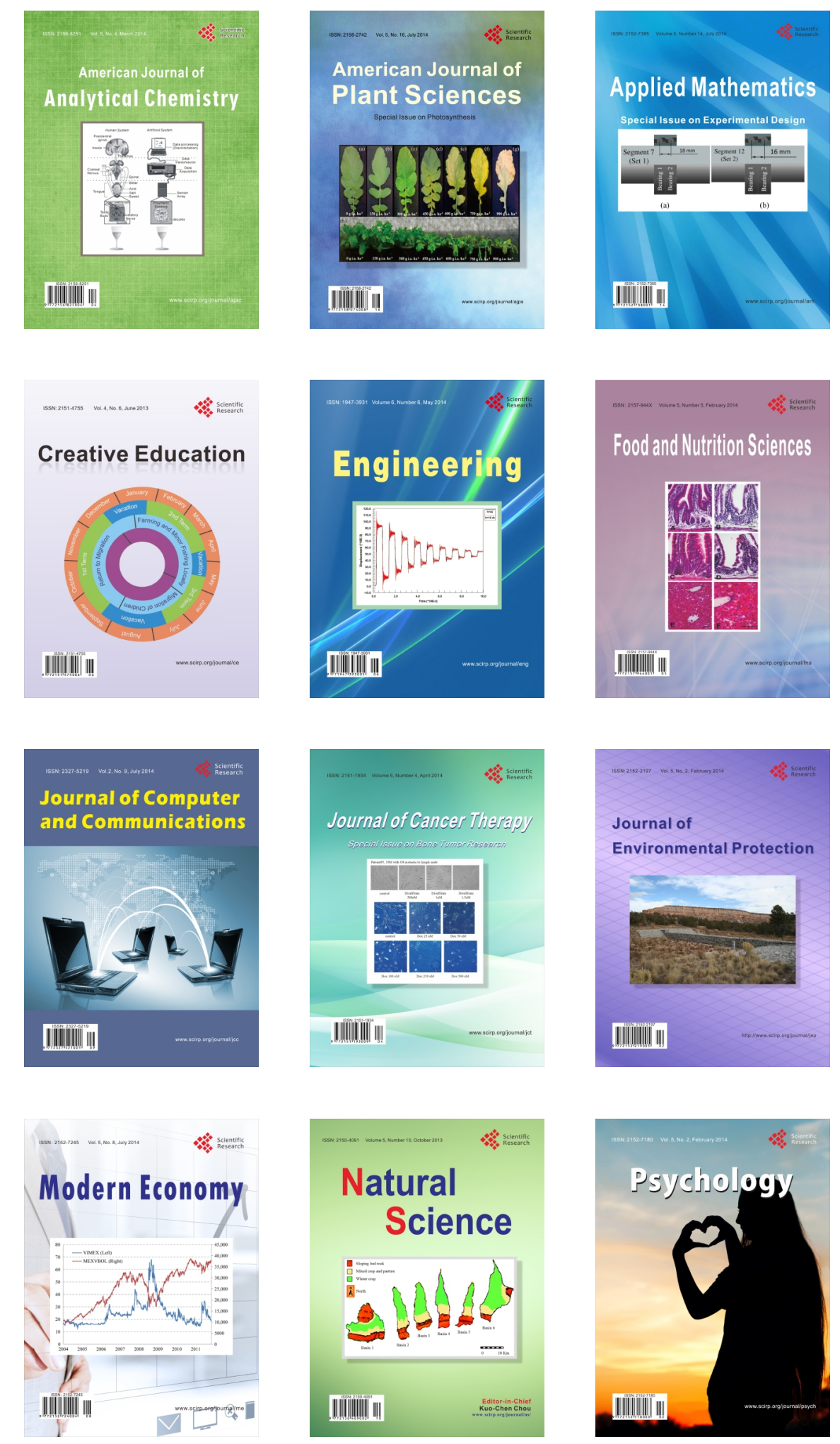